\title{
Use of Docent Strategies with Semi-Automated Didactic Tool for the Teaching and Learning of Renewable Energies
}

\author{
Rodrigo Florêncio da Silva* \\ Instituto Politécnico Nacional \\ CENLEX Zacatenco - CIIEMAD \\ Ciudad de México, México \\ rodriggo_florencio@hotmail.com \\ *Corresponding author \\ Pedro Joaquin Gutiérrez-Yurrita \\ Instituto Politécnico Nacional \\ CIIEMAD \\ Ciudad de México, México \\ pedro_joaquin_gutierrez@yahoo.com.mx
}

\author{
Juan Antonio Carmona \\ Instituto Politécnico Nacional \\ CIIEMAD \\ Ciudad de México, México
}

\author{
Luz Arcelia Garcia Serrano \\ Instituto Politécnico Nacional \\ CIIEMAD \\ Ciudad de México, México \\ drraipn@gmail.com
}

\begin{abstract}
This study describes the teaching of the renewable energies from an integrating view during lessons given in Mexican universities to students from different disciplines $s$ of knowledge. During the lessons a number of prototypes, as well as didactic pedagogical and technological materials were developed from a docent strategy for its use in courses given to students who enrolled and accepted to take part in these activities. The data obtained from the students and its further analysis showed that it is possible to teach the different renewable energies using a variety of didactic, pedagogical and technological tools.
\end{abstract}

Keywords-docent strategies; renewable energies; didactic tools; pedagogical tools; technological tools; environment

\section{INTRODUCTION}

Our modern world faces environmental problems which, unfortunately, have been mostly caused by human beings. Among these problems are the increasing global warming and the climate change, water shortages and droughts and the problems of agriculture related to water. There are also the pollution of oceans, seas and rivers and the high consumption of energy in the planet [1]. These circumstances lead to face the need of developing and environment education so that the international society can insert itself in the globalized world [2]. Environment education has been around for more than 50 years and it has contributed to the sustainability of the environment by means of the diffusion of information aimed at the development of abilities [3].

Due to the increasing needs of energy I all countries as a result of the development of technology, the exploitation of fossil fuels has grown. This has resulted in more environmental problems which can be reduced by the generalized use of renewable energies [4]. As a result, the work on renewable energies has gained momentum. The way to overcome those problems seems to be the effective use of renewable energies and the development of population awareness I this respect[5].

The acquisition of knowledge about the environment and its fundamental issues lead students to think about the problems that our planet is facing due to the high consumption of energy as well as to look for solutions to these questions [6]

During the process of learning about the environment and its issues the individual develops a better understanding of his interactions with the environment and the actions to take care of it. This results in a monitoring process of the effects that the student is learning [3]. In consequence, his social awareness grows and it is reflected in an improvement of factors such as a better care of the use of non-renewable products or those actually being modified by alarming entropic values.

Hence, there is a need to foster a better understanding of the learning-teaching process of the subjects related to renewable energies by means of a docent strategy in such a way that the student is more than a mere repeater of the teacher's words, i.e., a person able to harmonize the knowledge he is acquiring through the study of the subject. For that reason, this work presents a docent strategy which uses semi-automated didactic tools which support the teaching of the subject of renewable energies, it encompasses the use of conventional Information and Communication Technologies (ICT) as well as those generated during this research, including the elaboration of a set of devices to be evaluated as technological tools.

\section{METHODOLOGY}

In this work, a docent strategy is designed to enable the possibility of facilitating the teaching-learning process of the subject matters related to renewable energies. The strategy has 
a dynamic character which allows it to be adapted to different contexts and subjects related to the environment. This design uses a model of docent strategies based on problems, projects and both in-situ and ex-situ technologies.

For this research paper it was necessary to analyze previous successful works which used ICT's as the paper “Teaching Renewable Energy Using Multimedia”[7] which showed the implementation of an electronic learning system in the area of renewable energetic resources, the research paper “Secondary School Teachers' Knowledge, Perceptions and Attitudes towards Renewable Energy in Jordan" [8] which developed tools to explore attitudes and perceptions of secondary school teachers about renewable energies through questionnaires.

For this research a docent strategy was developed aimed at a college student population of diverse disciplines of knowledge and schools both private and public. For such purpose we made a course titled "Approaching Renewable Energies". We made an invitation to students of different academic institutions. This research involved students from the following branches of engineering: Textile, Mechatronics, Robotics, Electronics, Aeronautics, Industrial Civil and Chemical as well as International Trade, Marketing, Turism, Economy, Medicine and Homeopathy, Literature, communication Sciences and Law. The universe of students contained 850 individuals which were divided into 18 groups where each major was represented. Some correlations were generated from the application of the proper methodology. The universe of students was also divided into Exact Sciences and Humanities.

In the first place, the groups were explained the requirements to take part in this research, which were academic level, willingness to participate and permanence in the groups throughout the investigation.

Next, they were given a for $m$ which contained questions about their age, gender, preferences towards environment sciences especially renewable energies, socio-economic level, place of professional development, work and address. The form also contained questions related to the topic of renewable energies. Most of the latter questions were about whether the students were able to identify the clean energies used in México, whether they knew the concept of renewable energies in everyday conversations and if they knew the different kinds of renewable energies there are and their relationship to technology. Then, the students were given a 50-question test which accounted for a 100 points score and the results were recorded into tables and plotted.

For the rubric of this questionnaire each question was worth 0.2 points.

The questions were given the same level of complexity as in the previous test and the didactic tools were generated in situ during the course.

The methodology was supported by the development of systems which use ICT's - Internet pages of ludic interaction, for the design of didactic robots, creation of mockups and videos which represented topics related to the preservation of the environment, renewable energies and printed materials.
The methodology of this work is based on an experimental part conformed by different stages like the design of didactic robots and the development of systems based on interactive ICT's presented in an interactive ludic web page.

Some dynamic mockups were created with the purpose of obtaining a 3D representation of the use of renewable energies which is a fundamental part of the disciplines related to the environment. Video systems recorded in situ were also generated where a portrait of the use of renewable energies is shown which even allows the participation of students.

A basic course including the fundamental concepts of the classroom-learning environment was elaborated. This involved the partial and final results of previous stages.

For this study, a docent strategy based on problems, projects and technology was developed both in situ and ex situ, with semi-automated didactic tools which favored the understanding of the renewable energies.

The methodology of this research included:

- The design of didactic robots;

- The development of systems based on ICT's, represented in ludic-interactive web page;

- The conformation of a 3D representation of the use of renewable energies at scale level (by means of dynamic mockups);

- A system of videos generated in situ, giving way to the representation of the use of renewable energies and even the non-renewable ones with the active integration of the students into the activities;

- The conformation of a basic course with fundament on the concepts of the classroom-workshop where the partial and final results from previous stages were incorporated, and finally the last stage which consisted in giving the course and the use of coaching techniques.

An induction to renewable energies was given by means of a docent strategy which involved the use of pedagogic and didactic tools (pedagogic and didactic materials).

The course is accompanied by a guide book written beforehand with holistic and ludic elements. During the course different kinds of evaluation were given to students. One of them has elemental hermeneutic processes and another contained rubrics to define the extents and limitations of students.

\section{RESULTS AND DISCUSSION}

Since the teaching of the topic of renewable energies did not follow a curricular approach but an approach to make students become owners of their own knowledge the results of the teaching-learning process based on the identification of a series of significant variables show so far that the level of sensitiveness favored an interdisciplinary correlation as well as the understanding of the use of environment friendly energies. 
Analyzing the results of the exams given at the end of the course with respect to the first exam where no particular strategy was used it was possible to detect an improvement in the scores.

A further analysis of the results of both exams and their comparison showed an improvement of $24 \%$ in the scores. In the first exam no information about the contents of the exam was given. For the second exam the didactic strategies were employed.

Using the results of the evaluation instruments we get a segment by segment analysis by major: $49 \%$.

The students of textile engineering got an improvement of

The students of Mechatronics got an improvement of $40.6 \%$.

The students of Electronics Engineering got an improvement of $35.5 \%$.

The students of Robotics Engineering got an improvement of $22.8 \%$.

The students of Aeronautics Engineering got an improvement of $37.5 \%$.

The students of Industrial Engineering got an improvement of $37 \%$.

The students of Civil Engineering got an improvement of $37 \%$.

The students of Chemical Engineering got an improvement of $27.2 \%$.

The students of International Relations got an improvement of $27.3 \%$.

The students of Marketing got an improvement of 33.9\%.

The students of Tourism got an improvement of $21.7 \%$.

The students of International Commerce got an improvement of $25.6 \%$.

The students of Economy got an improvement of 27.4\%.

The students of Medicine got an improvement of 28.1\%.

The students of Communication Sciences got an improvement of $26.2 \%$.

The students of Languages got an improvement of $23.9 \%$.

The students of Literature got an improvement of $28.9 \%$.

The students of Law got an improvement of $26.5 \%$.

The students of Textile Engineering got a significant improvement with respect to their first exam where only one student got less than $60 \%$ correct answers in the evaluation instrument. However, comparing their results with respect to the other majors, it was the population with the lowest level of improvement. It is worth mentioning too that the students of Textile Engineering also got the lowest scores in the first exam. Of the 59 students who took the first exam only 6 got more than $60 \%$ of correct answers.
The students of Robotics Engineering were the group with the highest scores in both exams. In the first exam, 23 out of 49 students got more than $60 \%$ correct answers and all 49 students got more than $60 \%$ correct answers in the second exam.

Analyzing the general results of both exact sciences and humanities we find that the students belonging to the group of exact sciences got the lowest scores in the first exam where no strategies were employed, but these same students got the highest scores in the second exam after the docent strategies were employed.

Using these results we made graphics to analyze the data obtained by means of the questions about renewable energies. Considering all the data thus obtained we can say that most participants in this research are open to learning using these strategies.

\section{CONCLUSION}

This work had as aim to investigate the use of a docent strategy based on semi-automated tools for the teachinglearning of renewable energies with a population of 850 students belonging to different majors and colleges in México. By using the methodology of this study, supported by didactic robots, the development of systems based on ICT's represented in ludic interactive web pages, 3D representations of the use of clean energies in dynamic mockups, videos and the basic induction courses, new knowledge, perceptions and attitudes were generated in students towards energy sources.

By means of the courses organized (in informal environments), the students were given lessons and sustained constructive debates about the diverse renewable energies and their impact to the environment with their peers.

As a preliminary result we can say that the level of sensitivity obtained with this strategy favor the level of interdisciplinary correlation as well as the understanding of the disciplines related to the environment.

The items above and the development of this research show some results which helped approach the students by means of the strategy employed here.

We can say that the didactic strategies were applicable by the docent in different topics in different contexts and thematic with the students' population. In this case, “The Docent Strategy with Semi-automated Tools for the Teaching and Learning of the Renewable Energies" was used with the purpose of contributing to the students' formation concerning renewable energies.

During the investigation with the students who took part in the study it was possible to create a space for the construction of meanings about renewable energies and the contextualization and diffusion of the topic, this allowing students to take into consideration the existing conditions in which they get involved, thus allowing the use of real examples.

The resources and media used during this research gave way to some kind of formation in students in which they were 
participants, raising awareness in the environment and interest in the use of renewable energies.

\section{REFERENCES}

[1] J.Gutiérrez, S. Calvo, and J. Benayas. "Educación para el Desarrollo Sostenible: evaluación de retos y oportunidades del decenio 2005-2014". Revista Iberoamericana de educación, vol. 40, pp.26-69, Jan.2006.

[2] L.Sauvé, "La educación ambiental y la globalización: Desafíos curriculares y pedagógicos." Revista iberoamericana de educación, vol.41, pp. 83-101, May. 2006.

[3] K.Crohn, and M. Birnbaum. "Environmental education evaluation: time to reflect, time for change”. Evaluation and Program Planning, vol.33.2, pp.155-158, May.2010.

[4] C. Angeles-Camacho, and, O.A. Jaramillo. Granjas Eólicas. México: Editora Terracota, 2012, pp. 08-09.

[5] P.Jennings. "New directions in renewable energy education”. Renewable Energy, vol.34.2, pp.435-439, Feb.2009.

[6] C. Acikgoz, "Renewable energy education in Turkey". Renewable Energy, vol. 36.2, pp. 608-611, Feb.2011.

[7] B. Hadzi-Kostova, B., and, Z.A. Styczynski. "Teaching renewable energy using multimedia”. In Power Systems Conference and Exposition, IEEE, 2004, pp. 843-847.

[8] A. Zyadin, A. Puhakka, P. Ahponen, and P. Pelkonen. "Secondary school teachers' knowledge, perceptions, and attitudes toward renewable energy in Jordan”. Renewable Energy, vol. 62, pp.341-348, Feb.2014. 